\title{
Synthesis and Characterization of Carbon Nanospheres
}

\author{
Priya Karna1, Madhav Ghimire $^{2}$, Sanjay Mishra², Sunil Karna ${ }^{1}$ \\ ${ }^{1}$ Department of Natural Science, Union College, Barbourville, KY, USA \\ ${ }^{2}$ Department of Physics, University of Memphis, Memphis, TN, USA \\ Email: skarna@unionky.edu
}

How to cite this paper: Karna, P., Ghimire, M., Mishra, S. and Karna, S. (2017) Synthesis and Characterization of Carbon Nanospheres. Open Access Library Journal, 4: e3619. https://doi.org/10.4236/oalib.1103619

Received: April 18, 2017

Accepted: May 19, 2017

Published: May 22, 2017

Copyright (c) 2017 by authors and Open Access Library Inc.

This work is licensed under the Creative Commons Attribution International License (CC BY 4.0).

http://creativecommons.org/licenses/by/4.0/

\section{(c) (i) Open Access}

\begin{abstract}
An experiment was conducted to synthesize carbon nanospheres of different sizes by controlling the temperature in polycondensation reactions of glucose under hydrothermal processes. Morphological, structural, thermal, and optical properties of as-synthesized particles were characterized using a transmission electron microscope (TEM), scanning electron microscope (SEM), X-ray diffractometer (XRD), thermal gravimetric analysis (TGA), diffraction thermal analysis (DTA), and Raman spectroscopy. Thermal study indicates that particles change their phase from amorphous to crystalline before achieving a thermal stability at $520^{\circ} \mathrm{C}$. The presence of D-band and G-band in the Raman spectrum also verifies amorphous and crystalline natures of the sample. It has also been observed that the particle's morphology, dispersity, and size were modified after calcination of samples at $500^{\circ} \mathrm{C}$ in comparison to those not calcinated. Overall results indicate that the carbon nanospheres are hard solids and highly dispersed with size ranges from $50 \mathrm{~nm}$ to $260 \mathrm{~nm}$.
\end{abstract}

\section{Subject Areas}

Nanometer Materials

\section{Keywords}

Carbon Nanosphere, X-Ray Diffraction, TGA

\section{Introduction}

Carbon, a life forming element on earth, has ability to bond to itself. This property can be used to produce a myriad of structures that can be exploited in medical and energy applications. Carbon has many natural structures such as soot, an amorphous structure, diamond, a crystalline structure, and graphite, a honeycomb lattice structure. It is possible to synthesize carbon of such structures 
with different shape and size by mere control of carbon containing reactants and experimental conditions. The past two decades have witnessed a number of breakthroughs in carbon research that include fullerenes, graphene, and nanotubes. With the continuing technological developments and understanding the properties of carbon, scientists are able to synthesize verities of carbon containing materials from the micrometer to nanometer range [1]-[8]. The shape and size of carbon nanomaterials can easily be tuned during the growth process to produce carbon nanoparticles in the form of nanotubes, nanoflakes, nanoplates, nanorods, nanoballs, nanoonions, nanospheres, and many more. Among all these shapes and sizes, carbon nanospheres (CNs) show potential applications in optoelectronics, medicines, gas storage and sensors, heterogeneous catalysts, and encapsulating electrodes [1] [4] [9] [10].

Carbon nanospheres (CNs) are dispersible in water, and have shown high efficiency to breach the nuclear membrane while transporting drug molecules into the cell. The CNs are also intrinsically fluorescent and can be tracked easily inside cells without using any fluorescent tags [11]. One of the major problems in the synthesis of carbon nanospheres is their agglomeration in nanorange. Hence, we have used a developed synthesis technique to fine tune the intrinsic properties of CNs by changing their size and crystallinity.

\section{Experiment}

Various synthesis processes have been developed for carbon nanomaterials such as chemical vapor deposition (CVD), polymer pyrolysis, and hydrothermal treatment. Here we have used a hydrothermal (HTs) treatment to control the shape and size of CNs. We aim to tune the size and dispersion of CNs by controlling the growth parameters in HTs processes. The controlled size, monodispersity, chemical composition, and microscopic structure of a synthesized product can improve the performance of many devices like electrodes, photothermal materials, drug delivery carriers, and so on. Size of CNs in HTs processes can be controlled by adjusting the concentration of carbohydrate (glucose) solution, reaction time, and/or temperature. The synthesis process may be regarded as "green-chemistry," as it uses no toxic solvents or surfactants [3] [12] [13] [14] [15].

We have synthesized carbon nanospheres by polycondensation reactions of glucose under hydrothermal conditions. Fifty $\mathrm{mL}$ of $0.5 \mathrm{M}$ aqueous solution of glucose was kept in a $100 \mathrm{~mL}$ Teflon lined autoclave and heated for 6 hours at $140^{\circ} \mathrm{C}$ to $190^{\circ} \mathrm{C}$. The autoclave was cooled to room temperature before centrifuging the brown products with water. Finally, the product was rinsed in ethanol and dried at $60^{\circ} \mathrm{C}$ for 5 hours. The morphological, structural, thermal, and optical properties of as-synthesized particles were characterized using a transmission electron microscope (TEM), scanning electron microscope (SEM), X-ray diffractometer (XRD), thermal gravimetric analysis (TGA), diffraction thermal analysis (DTA), and Raman spectroscopy. 


\section{Results and Discussion}

The TEM images indicate that the carbon spheres are hard solids and are highly dispersed with size ranges from $50 \mathrm{~nm}$ to $260 \mathrm{~nm}$ on average. The samples which were calcinated at $500^{\circ} \mathrm{C}$ after a synthesis process have shown an improvement in surface morphology, reduction in size, and enhancement in dispersion compared to those which were not heat treated. The TEM images (a, b, c) in Figure 1 represent CNs synthesized at $170^{\circ} \mathrm{C}, 180^{\circ} \mathrm{C}$, and $190^{\circ} \mathrm{C}$, respectively for 6 hours in hydrothermal pot. The TEM images $(\mathrm{a}, \mathrm{b}, \mathrm{c})$ in Figure 2 were calcinated at $500^{\circ} \mathrm{C}$ in nitrogen atmosphere after the synthesis process. In Figure 3, TEM image (a) represents $\mathrm{CNs}$ synthesized at $160^{\circ} \mathrm{C}$, SEM image (b) represents $\mathrm{CNs}$ synthesized at $140^{\circ} \mathrm{C}$, and a histogram (c) represents size distribution of as synthesized carbon nanospheres before and after calcination. A node-like structure on the surface of a particle in Figure 3(a) may be responsible for interconnection of carbon spheres. The SEM images shown in Figure 3(b) possess highly porous hollow particles of sponge-like surface indicating immature particles with the size range in micrometer. This sample was grown at $140^{\circ} \mathrm{C}$ for 6 hours.
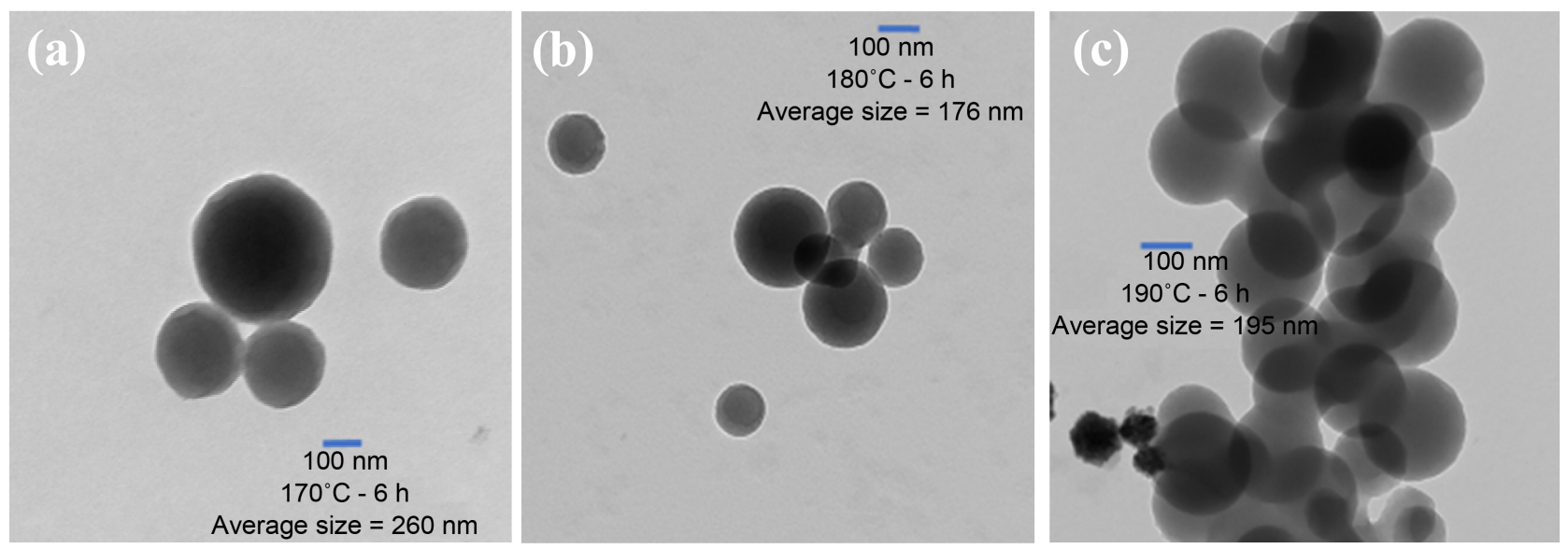

Figure 1. TEM images for as synthesized CNs for 6 hours, images (a), (b), and (c) represent the CNs synthesized at temperature $170^{\circ} \mathrm{C}, 180^{\circ} \mathrm{C}$, and $190^{\circ} \mathrm{C}$, respectively.
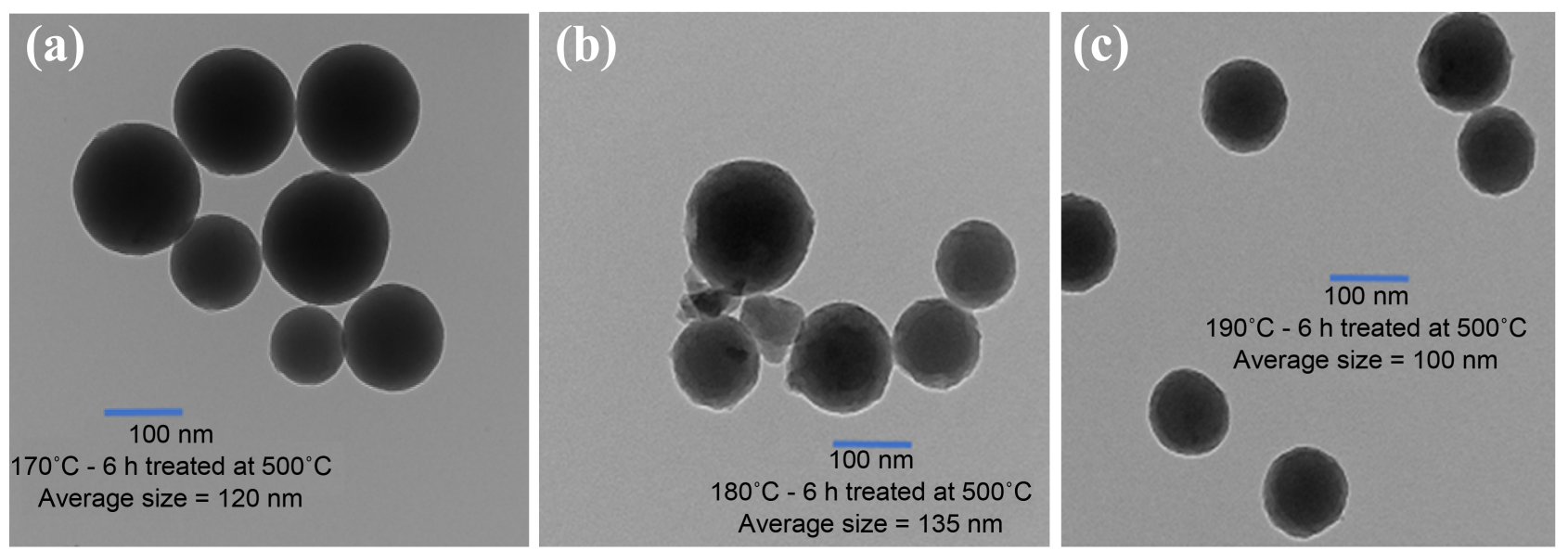

Figure 2. TEM images for CNs calcinated at $500^{\circ} \mathrm{C}$, images (a), (b), and (c) represent the CNs synthesized for 6 hours at temperature of $170^{\circ} \mathrm{C}, 180^{\circ} \mathrm{C}$, and $190^{\circ} \mathrm{C}$, respectively. 

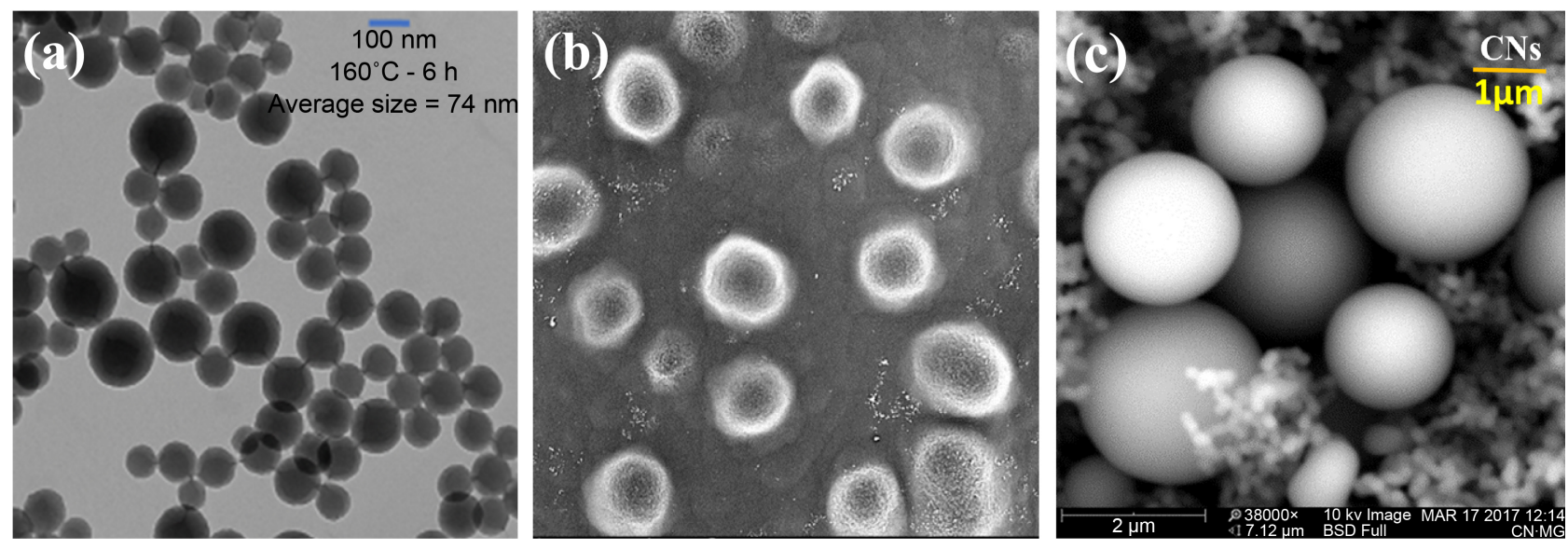

Figure 3. Image (a) is the TEM of CNs synthesized at $160^{\circ} \mathrm{C}$ for 6 hours, image (b) and (c) are the SEM of CNs synthesized at $140^{\circ} \mathrm{C}$ for 6 hours, and that at $170^{\circ} \mathrm{C}$ for 15 hours, respectively.

The surface morphology and porosity of spheres seem to form "a pool of thread" while growing at elevated pressure in the polycondensation reaction. In polycondensation reactions, carbon containing materials may have formed a long polymer chain which would curl up around a "seed" to form carbon spheres until the conditions are favorable. As this temperature was not favorable to grow $\mathrm{CNs}$ for 6 hour durations, we have continued our experiment from $160^{\circ} \mathrm{C}$ to $190^{\circ} \mathrm{C}$. However, the particle grown at $170^{\circ} \mathrm{C}$ for 15 hours has a good surface morphology but extra-large size which is not of our interest at this time as shown in Figure 3(c). The histogram in Figure 4(b) depicts that $170^{\circ} \mathrm{C}$ was the optimal condition to grow carbon nanospheres in our experimental setup.

The X-ray diffraction patterns of the sample contains a strong peak at $11.6^{\circ}$ and weak peak at $22.2^{\circ}$ associated to (002) as shown in Figure 4(a) and (110) reflection planes in a tetragonal arrangement of carbon atoms. The XRD was taken with $\mathrm{Cu}-\mathrm{K}_{\alpha}(\lambda=1.5406$ Angstrom) radiation and the Raman spectrum as shown in inset of Figure 4(a) was recorded using $514 \mathrm{~nm}$ laser excitation at the room temperature. Raman spectrum of carbon spheres grown at $140^{\circ} \mathrm{C}$ comprises sharp peaks at $1580 \mathrm{~cm}^{-1}$ (G-Band) representing a graphitic structure followed by a broad shoulder at $1330 \mathrm{~cm}^{-1}$ (D-Band), which corresponds to the presence of both $\mathrm{sp}^{2}$ and $\mathrm{sp}^{3}$ hybrid carbons and minor peaks correspond to amorphous carbon structure. The TGA/DTA curves as shown in Figure 5 were taken in $\mathrm{N}_{2}$ atmosphere at a heating rate of $15^{\circ} \mathrm{C} / \mathrm{min}$. The TGA was performed to determine the thermal behavior of carbon nanospheres [16]. The TGA curves indicate a slow rate of weight loss up to $160^{\circ} \mathrm{C}$ indicating the evaporation of volatile substance and water contents in the samples. Between $160^{\circ} \mathrm{C}$ and $260^{\circ} \mathrm{C}$, the samples may have released nitrogen or oxygen contents. Weight loss down to $520^{\circ} \mathrm{C}$ indicates a phase change of carbon materials from amorphous to crystalline structure. The sample achieved thermal stability above $520^{\circ} \mathrm{C}$. Fast weight loss at $265^{\circ} \mathrm{C}$ results from a TGA of CNs grown at $170^{\circ} \mathrm{C}$ for 15 hours, but only $20 \%$ of weight loss has been observed. Such fast weight loss can support the idea of hard solid spheres. Two broad exothermic peaks of the DTA curve at $320^{\circ} \mathrm{C}$ 

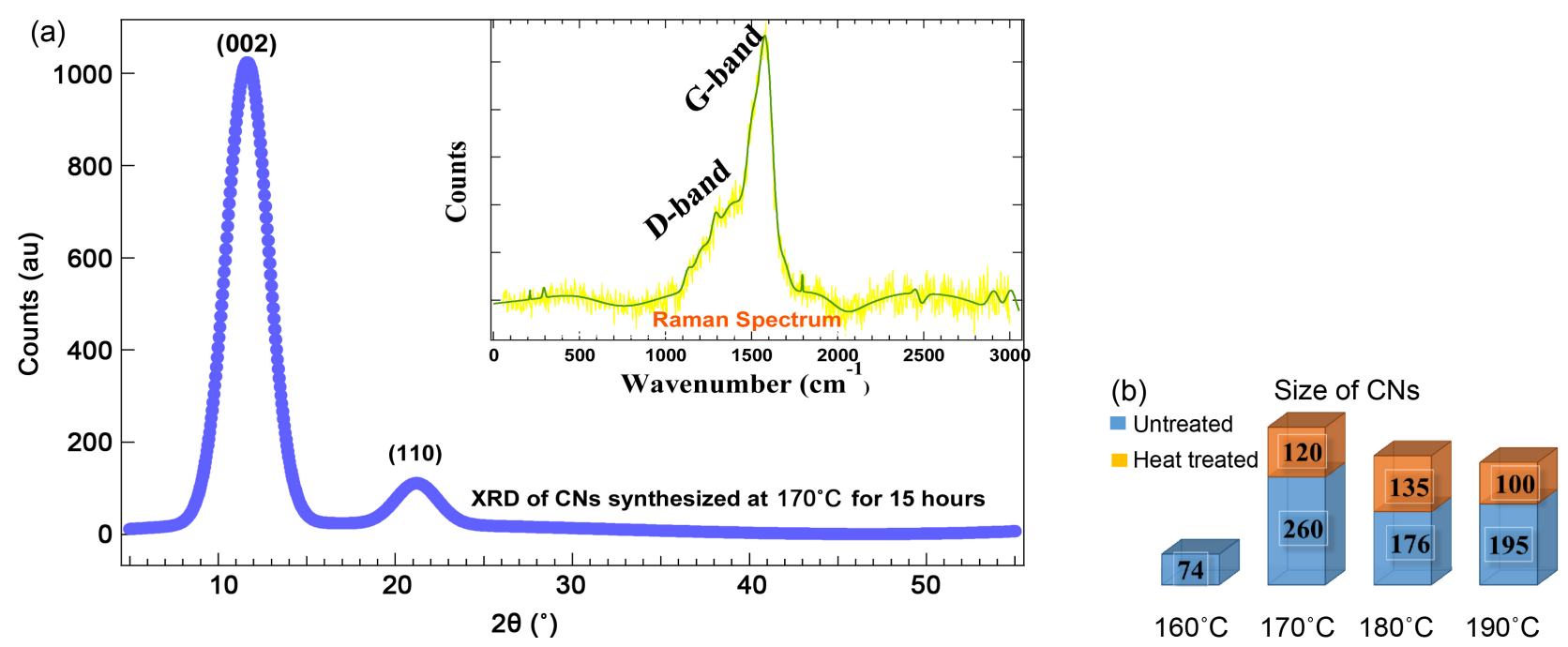

Figure 4. The XRD patterns of CNs synthesized at $170^{\circ} \mathrm{C}$ for 15 hours, figure (a), and inset shown in figure (a), is the Raman spectrum of CNs synthesized at $140^{\circ} \mathrm{C}$ for 6 hours, and a histogram of size distribution of CNs before (bottom bar) and after (top bar) heat treatment, figure (b).

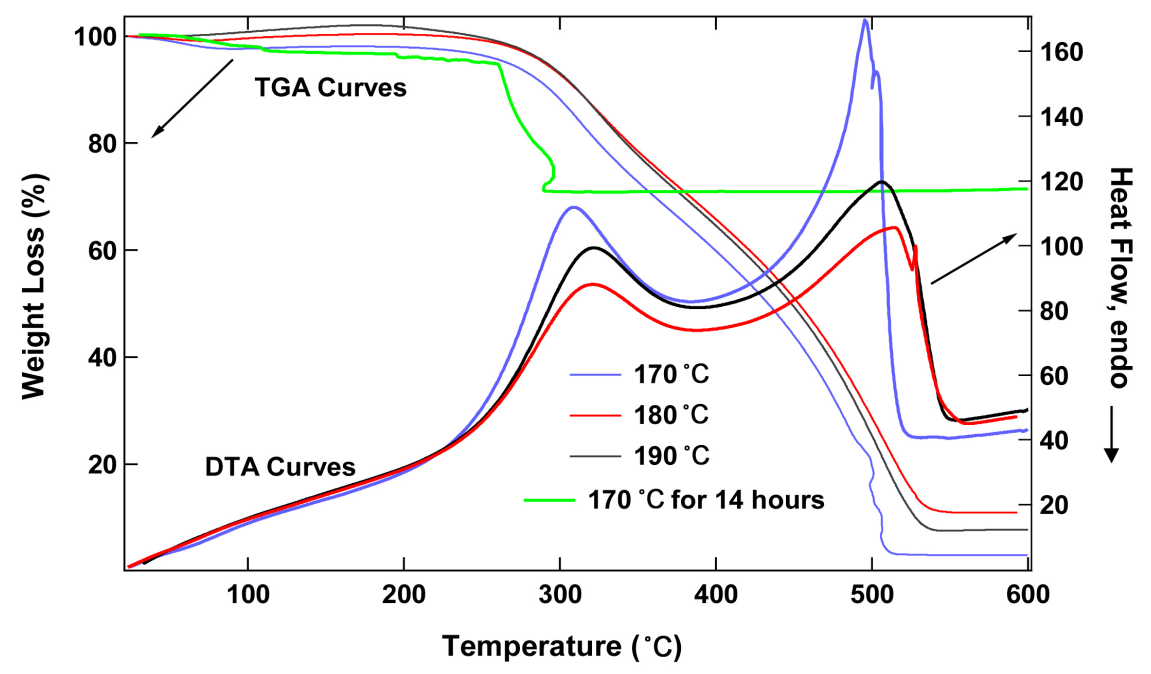

Figure 5. TGA/DTA Curve taken in $\mathrm{N}^{2}$ atmosphere at heating rate of $15^{\circ} \mathrm{C} / \mathrm{min}$.

and $500^{\circ} \mathrm{C}$ indicate the phase transition of samples from amorphous to crystalline, and a thermally stable structure of nanospheres, respectively.

\section{Conclusion}

Carbon nanospheres with clean surface morphology were successfully synthesized using a green-chemistry method. This method involves the hydrothermal decomposition of glucose in water at considerably low temperatures from $140^{\circ} \mathrm{C}$ to $190^{\circ} \mathrm{C}$. The product obtained was characterized by TEM, SEM, TGA, X-ray diffraction, and Raman spectroscopy. The TEM images indicate that the carbon spheres are hard solids and highly dispersed with size ranges from $50 \mathrm{~nm}$ to 260 $\mathrm{nm}$ on average. The carbon nanospheres synthesized at $170^{\circ} \mathrm{C}$ for 6 hours have shown high quality. Carbon active centers on the surface of spheres may be the 
cause of fusion of two spheres as seen on the sample grown at $160^{\circ} \mathrm{C}$. The presence of a D-band and a G-band in the Raman spectrum supports the TGA/DTA curves which indicate the thermal stability of carbon spheres and phase transition from amorphous to crystalline structure. Our study shows that the post heat treatment of hydrothermally synthesized carbon nanospheres will enhance the surface morphology, reduce the particle size, and become well dispersed.

\section{Acknowledgements}

I would like to thank Faculty Research Committee at Union College, Barbourville, KY to provide funds for this research. I would also like to thank Dr. Dan Covington, Dr. Rob Chandler, and Dr. Keith Stafford for their support during project work.

\section{References}

[1] Pan, K., Ming, H., Liu, Y. and Kang, Z. (2012) Large Scale Synthesis of Carbon Nanospheres and their Application as Electrode Materials for Heavy Metal Ions Detection. New Journal of Chemistry, 36, 113-118. https://doi.org/10.1039/C1NJ20756C

[2] Poinern, G., Brundavanam, S., Shah, M., Laava, I. and Fawcett, D. (2012) Photothermal Response of CVD Synthesized Carbon (Nano) Spheres/Aqueous Nanofluids for Potential Application in Direct Solar Absorption Collectors: A Preliminary Investigation. Nanotechnology, Science and Applications, 5, 49-59. https://doi.org/10.2147/NSA.S34166

[3] Sun, X. and Li, Y. (2004) Colloidal Carbon Spheres and Their Core/Shell Structures with Noble-Metal Nanoparticles. Angewandte Chemie International Edition, 43, 597-601. https://doi.org/10.1002/anie.200352386

[4] Deshmukh, A., Mhlanga, S. and Coville, N. (2010) Carbon Spheres. Materials Science and Engineering, 70, 1-28. https://doi.org/10.1016/j.mser.2010.06.017

[5] Coville, N., Mhlanga, S., Nxumalo, E. and Shaikjee, A. (2011) A Review of Shaped Carbon Nanomaterials. South African Journal of Science, 107, 1-15. https://doi.org/10.4102/sajs.v107i3/4.418

[6] Qu, L., Zhang, H., Zhu, J. and Dai, L. (2010) Tunable Assembly of Carbon Nanospheres on Single-Walled Carbon Nanotubes. Nature Nanotechnology, 21, 30.

[7] Raza, A., Wang, J., Yang, S., Si, Y. and Ding, B. (2014) Hierarchical Porous Carbon Nanofibers via Electrospinning. Carbon Letters, 15, 1-14.

https://doi.org/10.5714/CL.2014.15.1.001

[8] Zheng, P., Qiao, Z. and Dai, S. (2015) Recent Advances in Carbon Nanospheres: Synthetic Routes and Applications. Chemical Communications, 51, 9246-9256.

[9] Zheng, G., et al. (2014) Interconnected Hollow Carbon Nanospheres for Stable Lithium Metal Anodes. Nature Nanotechnology, 9, 618-623. https://doi.org/10.1038/nnano.2014.152

[10] Neumann, O., et al. (2013) Solar Vapor Generation Enabled by Nanoparticles. ACS Nano Letters, 7, 42-49. https://doi.org/10.1021/nn304948h

[11] Selvi, B., et al. (2008) Intrinsically Fluorescent Carbon Nanospheres as a Nuclear Targeting Vector: Delivery of Membrane-Impermeable Molecule to Modulate Gene Expression In Vivo. Nano Letters, 8, 10.

[12] Karami, M., Raisee, M., Delfani, S., Akhavan, M. and Rashidi, A. (2013) Sunlight Absorbing Potential of Carbon Nanoball Water and Ethylene Glycol-Based Nanof- 
luids. Optics and Spectroscopy, 115, 3. https://doi.org/10.1134/S0030400X13090105

[13] Li, M., Wu, Q., Wen, M. and Shi, J. (2009) A Novel Route for Preparation of Hollow Carbon Nanospheres without Introducing Template. Nanoscale Research Letters, 4 , $1365-1370$.

[14] Wang, X., Hu, C., Xiong, Y. and Zhang, C. (2013) Synthesis of Functional Carbon Nanospheres by a Composite-Molten-Salt Method and Amperometric Sensing of Hydrogen Peroxide. Journal of Nanoscience and Nanotechnology, 13, 933-936. https://doi.org/10.1166/jnn.2013.6003

[15] Zhang, L., Qiang, S., Chao, Y. and An-Hui, L. (2015) Synthesis of Magnetic Hollow Carbon Nanospheres with Superior Microporosity for Efficient Adsorption of Hexavalent Chromium Ions. Science China Materials, 58, 611-620.

[16] Sharma, S. and Mudhoo, A. (2011) A Handbook of Applied Biopolymer Technology. RSC Publishing, Cambridge, 223. https://doi.org/10.1039/9781849733458

Submit or recommend next manuscript to OALib Journal and we will provide best service for you:

- Publication frequency: Monthly

- 9 subject areas of science, technology and medicine

- Fair and rigorous peer-review system

- Fast publication process

- Article promotion in various social networking sites (LinkedIn, Facebook, Twitter, etc.)

- Maximum dissemination of your research work

Submit Your Paper Online: Click Here to Submit

Or Contact service@oalib.com 